\title{
ANALISIS POLA PENJUALAN DENGAN MENGGUNAKAN ALGORITMA APRIORI PADA KOPERASI KARYAWAN YAYASAN ANAKKU
}

\author{
Arfianto Darmawan'; Titin Kristiana ${ }^{2}$ \\ Program Studi Sistem Informasi \\ STMIK Nusa Mandiri Jakarta \\ http://nusamandiri.ac.id \\ 1darmawanarfianto@gmail.com; 2titin.tka@nusamandiri.com
}

\begin{abstract}
Abstrak
Koperasi Yayasan Anakku adalah sebuah koperasi serba usaha yang terdiri dari usaha toko, simpan pinjam, dan jasa antar jemput siswa. Setiap penjualan barang/jasa akan dilakukan penginputan data secara langsung pada masing-masing unit usaha tersebut. Pada unit usaha toko data yang besar ini masih memiliki kendala, diantaranya transaksi toko belum bisa menjawab barang-barang apa yang sering terjual secara bersamaan, saat stock barang masih sulit menentukan barang-barang yang masih tersedia atau hampir menipis persediaannya. Teknik Data mining telah banyak digunakan untuk mengatasi permasalahan yang ada, salah satunya dengan penerapan algoritma Apriori untuk mendapatkan informasi tentang asosiasi antar produk dari suatu database transaksi. Data transaksi penjualan perlengkapan sekolah di Koperasi Karyawan Yayasan Anakku dapat diolah kembali menggunakan aplikasi Data mining sehingga menghasilkan aturan asosiasi keterkaitan yang kuat antar itemset penjualan perlengkapan sekolah sehingga bisa memberi rekomendasi penyetokan barang dan mempermudah dalam penataan atau penempatan barang yang kuat berkaitan saling ketergantungan. Hasil dari penelitian ini menemukan Nilai support dan confidence tertinggi adalah jika membeli BAHAN MUSLIM L1.5P1 maka akan membeli LOGO AL-IZHAR II dengan nilai support $14,5 \%$ dan confidence 79,5\%.
\end{abstract}

Kata Kunci : Koperasi Karyawan Yayasan Anakku, Transaksi Penjualan Perlengkapan Sekolah, Data mining, Algoritma Apriori

\begin{abstract}
The Anakku Foundation Cooperative is a multi-business cooperative consisting of shop businesses, savings and loans, and student shuttle services. Every sale of stuff services will be inputted data directly to each business unit. The Anakku Foundation Cooperative still has problems, including store transactions that cannot yet answer what items are often sold, when stock items are still difficult to determine the items that are still available or almost running out. Data mining techniques have been mostly used to overcome existing problems, one of which is the application of the Apriori algorithm to obtain information about the associations between products from a transaction database. Transaction data on school equipment sales at Cooperative Employees of Anakku Foundation can be reprocessed using Data mining applications so as to produce strong association rules between itemset sales of school supplies so that they can provide recommendations for item alignment and simplify the arrangement or strong item placement related to interdependence. The results are found that the highest value of support and confidence is if buying MUSLIM L1.5P1, so it would buy AL-IZHAR II LOGO with a value of $14.5 \%$ support and $79.5 \%$ confidence.
\end{abstract}

Keywords : Yayasan Anakku employee coperative, School Equipment Sales Transactions, Data mining, Apriori Algorithm

\section{PENDAHULUAN}

Perlengkapan sekolah merupakan kebutuhan utama bagi siswa yang akan memasuki dunia pendidikan dasar dan menengah. Kebutuhan perlengkapan sekolah banyak jenis dan ragamnya Seperti: baju seragam, baju olah raga, logo sekolah, sepatu, kaos kaki, buku pelajaran, dan masih banyak lainnya. Kebutuhan perlengkapan sekolah tersebut merupakan kewajiban yang harus dipenuhi siswa ketika pihak sekolah sudah menentukan peraturan yang telah ditetapkan. Pihak sekolah menetapkan perlengkapan sekolah yang harus dipenuhi siswa pada dasarnya merupakan upaya sekolah dalam hal kedisiplinan, misalnya dalam pemakaian baju seragam, menjaga identitas sekolah, membangun karakter siswa, dan dapat membangun kebersamaan antar siswa selama menempuh pendidikan di lembaga pendidikan tersebut. Oleh karena itu pihak 
sekolah harus menyediakan kebutuhan perlengkapan sekolah bagi seluruh siswa dan menjamin adanya ketersediaan barang-barang tersebut supaya terjaga keseimbangan antara permintaan (Wijayanti, Nur, \& B, 2016) dan penawaran atas kebutuhan tersebut. Salah satu upaya sekolah atas ketersediaan perlengkapan sekolah bagi siswa adalah dengan melakukan kerjasama dengan Koperasi yang ada dilingkungan sekolah tersebut. Koperasi yang didirikan oleh guru dan karyawan ini bernama Koperasi Karyawan Yayasan Anakku atau sering disebut Koperasi Al-Izhar. Koperasi Al-izhar merupakan jenis koperasi serba usaha yang memiliki bidang usaha Toko yang menyediakan berbagai macam kebutuhan baik untuk karyawan maupun siswa.

Dari usaha toko ini disediakan berbagai macam kebutuhan yang khusus diperlukan oleh para siswa seperti berbagai macam perlengkapan sekolah seperti: baju seragam, baju olah raga, logo sekolah, sepatu, kaos kaki, buku pelajaran, dan masih banyak lainnya. Dari berbagai perlengkapan sekolah yang ditawarkan kesiswa tersebut, Maka koperasi harus bisa mengemas/ mendisplay dengan baik dan tepat. Semua itu memiliki tujuan agar siswa atau orang tua siswa dapat mencari dengan cepat dan menjangkau setiap pilihan yang tepat dari berbagai jenis perlengkapan sekolah yang ditawarkan. Jadi pemasaran perlengkapan sekolah mempunyai strategi pemasaran sendiri untuk memikat ketertarikan pelanggan dari mulai penempatan barang yang paling banyak diminati, penentuan diskon, hingga penawaran harga lainnya.

Koperasi Karyawan Yayasan Anakku walaupun sudah lama berdiri dan berkembang, masih ditemukan permasalahan pada transaksi terutama dalam pengolahan data. Koperasi ini masih menggunakan data transaksi yang belum terkomputerasi (Nere \& Buani, 2018) dan laporan penjualan masih dibuat dengan secara manual sehingga kurang akuratnya laporan (Aediyansyah, 2018) dan memerlukan waktu yang lama (Lisnawanty \& Kurniawan, 2019). Koperasi mengalami kesulitan dalam mengolah data transaksi yang banyak. Beberapa permasalahan yang sering muncul mengenai penjualan, yaitu ketersediaan data penjualan yang besar tidak digunakan secara maksimal karena belum adanya sistem pendukung keputusan (Sikumbang, 2018) dan belum adanya metode yang dapat digunakan untuk merancang sebuah strategis bisnis dalam meningkatkan penjualan. Setiap hari data transaksi penjualan di Indomaret semakin bertambah banyak sehingga data tersebut menumpuk (Susilo, 2018), Namun data ini seringkali diperlakukan hanya sebagai rekaman tanpa pengolahan lebih lanjut sehingga tidak mempunyai nilai guna lebih untuk bisa dimanfaatkan dengan baik. Untuk mengatasi masalah yang ada penulisan menggunakan metode Apriori (Oktaviani, TM Napitupul, Sarkawi, \& Yulianti, 2019). Analisis dari tiap koleksi data tersebut akan menghasilkan pengetahuan atau informasi, misalnya berupa pola dan kaidah asosiasi yang terjadi pada data.

\section{BAHAN DAN METODE}

\section{A. Tahapan Pengumpulan Data}

Penulis mengumpulkan referensi-referensi mengenai algoritma apriori dan melakukan observasi langsung di Koperasi Karyawan Yayasan Anakku. Setelah itu penulis melakukan sesi wawancara kepada salah satu pengurus toko, dan staf bagian toko mengenai hal-hal berkaitan dengan keberadaan Koperasi Karyawan Yayasan Anakku, seperti latar belakang berdirinya koperasi, masalah kepengurusan koperasi, penataan barang-barang toko, dan lain-lain.

\section{B. Populasi}

Populasi yang dimaksud dalam penelitian disini adalah keseluruhan transaksi penjualan barang-barang toko berupa produk perlengkapan sekolah selama 3 bulan (triwulan) terakhir dengan jumlah transaksi sebanyak 651 record, periode 2018.

\section{Sampel Penelitian}

Sampel yang akan diambil dari populasi tersebut harus betul-betul representatif atau dapat mewakili. Dalam penelitian ini penulis menggunakan sampel selama 3 bulan (triwulan) terakhir periode 2018 dengan transaksi sebanyak 242 record.

Tabel 1. Produk Koperasi Karyawan Yayasan Anakku

\begin{tabular}{cc}
\hline NO & PRODUK \\
\hline 1 & BAHAN ABU-ABU KOP \\
\hline 2 & BAHAN HIJAU SMU\& SMP \\
\hline 3 & BAHAN KOTAK-KOTAK KOP \\
\hline 4 & BAHAN MUSLIM LI.5P1 \\
\hline 5 & BUKU AGENDA KOP \\
\hline 6 & BUKU PENGHUBUNG KB \\
\hline 7 & BUKU PENGHUBUNG SD \\
\hline 8 & Celana OR Biru TK XL \\
\hline 9 & Celana OR Biru TK XXL \\
\hline 10 & Celana OR SD Biru L \\
\hline 11 & Celana OR SD Biru XL \\
\hline 12 & Celana OR SD Biru XXL \\
\hline 13 & celana OR SD XXXL \& XXXXL \\
\hline 14 & Celana OR SMA Biru L \\
\hline 15 & Celana OR SMA Biru M \\
\hline 16 & Celana OR SMA Biru S
\end{tabular}




\begin{tabular}{cc}
\hline 18 & Celana OR SMA Biru XL \\
\hline 19 & Celana OR SMA Biru XXL \\
\hline 20 & Celana OR SMA Biru XXXL \& XXXXL \\
\hline
\end{tabular}

1. Analisa Pola Frekuensi Tinggi

Pada tahapan ini mencari kombinasi item set yang memenuhi syarat minimum dari support. Nilai support sebuah item set diperoleh dengan rumus sebagai berikut :

$\left(\right.$ Support A) $=\frac{\sum \text { Jumlah Transaksi Mengandung A }}{\Sigma \text { Total Transaksi }}$ X100\%

Proses selanjutnya yaitu dengan mencari Nilai support dari 2 item set diperoleh dari rumus 2 item set berikut.

Support $(A, B)=P(A \cap B)$

$($ Support $(A, B))=\frac{\Sigma \text { Jumlah Transaksi Mengandung A dan B }}{\Sigma \text { Total Transaksi }}$ X100\%

Dalam pencarian pola frekuensi tinggi akan di hentikan apabila kombinasi tidak ada lagi yang memenuhi syarat minimum support yang telah ditentukan yaitu support $=3 \%$.

\section{Pembentukan Aturan Asosiasi}

Setelah proses pencarian pola frekuensi tinggi ditemukan, barulah mencari aturan asosiasi yang memenuhi syarat minimum untuk confidence dengan menghitung confidence aturan asosiatif $A \rightarrow B$ dengan minimum confidence $=30 \%$. Nilai confidence dari aturan $\mathrm{A} \rightarrow \mathrm{B}$ diperoleh dari rumus berikut:

$($ Confidence $\mathrm{P}(\mathrm{A} \mid \mathrm{B}))=\frac{\sum \text { Transaksi yang mengandung } \mathrm{A} \text { dan } \mathrm{B}}{\sum \text { Transaksi mengandung } \mathrm{A}} \mathrm{X} 100$

Setelah proses pencarian nilai confidence ditemukan, masuk ke tahapan terakhir yaitu mencari nilai lift rasio. Lift Ratio merupakan nilai yang menunjukkan kevalidan proses transaksi dan memberikan informasi apakah benar produk A dibeli bersamaan dengan produk B.

Lift / Improvement Ratio dapat dihitung dengan rumus berikut:

Nilai Lift $=\frac{\text { Support AnB }}{\text { Support }(A) X \text { Support }(B)}$

\section{HASIL DAN PEMBAHASAN}

\section{A. Pembuatan 1 Itemset}

Tabel 2. Daftar Support Final 1 Itemset

\begin{tabular}{lll}
\hline ITEM SET 1 & JUMLAH & SUPPORT \\
\hline BAHAN ABU - ABU KOP & 24 & 0,099 \\
\hline BAHAN HIJAU SMU \& SMP & 9 & 0,037 \\
\hline BAHAN KOTAK-KOTAK & 34 & 0,140 \\
\hline
\end{tabular}

\begin{tabular}{lll}
\hline ITEM SET 1 & JUMLAH & SUPPORT \\
\hline KOP & & \\
\hline BAHAN MUSLIM L1.5 P1 & 44 & 0,182 \\
\hline BUKU AGENDA KOP & 29 & 0,120 \\
\hline BUKU PENGHUBUNG SD & 17 & 0,070 \\
\hline KAOS KAKI NO: $17-18$ & 19 & 0,079 \\
\hline KAOS KAKI NO: $19-20$ & 47 & 0,194 \\
\hline KAOS KAKI NO: $21-22$ & 50 & 0,207 \\
\hline KAOS KAKI No: $23-24$ & 40 & 0,165 \\
\hline KAOS KAKI NO: $25-26$ & 26 & 0,107 \\
\hline KAOS KAKI NO: $27-28$ & 21 & 0,087 \\
\hline KEMEJA DOLAR NO 13 & 13 & 0,054 \\
\hline
\end{tabular}

B. Kombinasi 2 Itemset

Proses Pembentukan C2 atau disebut dengan 2 item set dengan jumlah minimum support $=3 \%$. Dapat diselesaikan dengan rumus berikut :

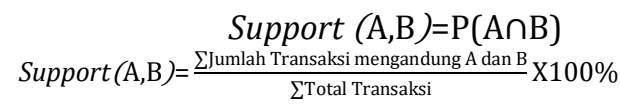

Berikut adalah perhitungan pembentukan 2 itemset;

Tabel 3. Daftar Support Final 2 Itemset

\begin{tabular}{lll}
\hline Itemset 2 & JUMLAH & SUPPORT \\
\hline BAHAN ABU - ABU KOP, & 13 & 0,054 \\
BAHAN KOTAK-KOTAK KOP & & \\
\hline $\begin{array}{l}\text { BAHAN KOTAK-KOTAK KOP, } \\
\text { BAHAN MUSLIM L1.5 P1 }\end{array}$ & 8 & 0,033 \\
\hline $\begin{array}{l}\text { BAHAN KOTAK-KOTAK KOP, } \\
\text { LOGO AL IZHAR II }\end{array}$ & 14 & 0,058 \\
\hline $\begin{array}{l}\text { BAHAN MUSLIM L1.5 P1, LOGO } \\
\text { AL IZHAR II }\end{array}$ & 35 & 0,145 \\
\hline $\begin{array}{l}\text { BUKU AGENDA KOP, BUKU } \\
\text { PENGHUBUNG SD }\end{array}$ & 14 & 0,058 \\
\hline $\begin{array}{l}\text { KAOS KAKI NO: 17-18, KAOS } \\
\text { KAKI NO: 19-20 }\end{array}$ & 11 & 0,045 \\
\hline $\begin{array}{l}\text { KAOS KAKI NO: 19-20, KAOS } \\
\text { KAKI NO: 21-22 }\end{array}$ & 15 & 0,062 \\
\hline $\begin{array}{l}\text { KAOS KAKI NO: 21-22, KAOS } \\
\text { KAKI No: 23-24 }\end{array}$ & 9 & 0,037 \\
\hline $\begin{array}{l}\text { KAOS KAKI No: 23-24, LOGO AL } \\
\text { IZHAR II }\end{array}$ & 8 & 0,033 \\
\hline $\begin{array}{l}\text { KAOS KAKI No: 23-24, TOPI } \\
\text { SD/SMP KOP }\end{array}$ & 10 & 0,041 \\
\hline
\end{tabular}

Dari hasil pencarian nilai support 2 itemset yang memenuhi minimal support 3\% hanya ada 10.

C. Kombinasi 3 Itemset

Proses pembentukan C3 atau disebut dengan 3 itemset dengan jumlah minimum support 3\%. Dapat diselesaikan dengan rumus sebagai berikut:

Support A,B dan C $\frac{\sum \text { Jumlah Transaksi Mengandung A,B dan C }}{\sum \text { Total Transaksi }}$ X100\%

Tabel 4. Daftar Support Final 3 Itemset

\begin{tabular}{lll}
\hline Itemset 3 & Jumlah & Support \\
\hline BAHAN ABU - ABU KOP, BAHAN & 3 & 0,01 \\
KOTAK-KOTAK KOP, BAHAN & & \\
MUSLIM L1.5 P1 & \\
\hline
\end{tabular}




\begin{tabular}{lll}
\hline Itemset 3 & Jumlah & Support \\
\hline BAHAN ABU - ABU KOP, BAHAN & 6 & 0,02 \\
KOTAK-KOTAK KOP, LOGO AL & & \\
IZHAR II & & \\
\hline BAHAN ABU - ABU KOP, BAHAN & 3 & 0,01 \\
KOTAK-KOTAK KOP, BAHAN & & \\
MUSLIM L1.5 P1 & & \\
\hline
\end{tabular}

Dari perhitungan tabel di atas hasil nilai support 3 itemset tidak memenuhi minimal support 3\% maka tidak di lanjutkan ke iterasi 4 . Jadi untuk meneruskan pembentukan asosiasi menggunakan hasil iterasi 2.

\section{Pembentukan Asosiasi}

Setelah semua pola frekuensi tinggi ditemukan, barulah dicari aturan asosiasi yang memenuhi syarat minimum untuk confidence dengan menghitung confidence aturan asosiatif A $\rightarrow$ B. Minimal confidence yang ditentukan adalah $30 \%$, dengan lift ratio 1,1 . Untuk mengetahui nilai confidence, dapat ditentukan dengan rumus berikut:

confidence $=\mathrm{P}(\mathrm{B} \mid \mathrm{A}) \frac{\sum \text { Transaksi mengandung A dan B }}{\sum \text { Transaksi mengandung A }} \mathrm{X} 100 \%$

Perhitungan confidence dilakukan dengan mengambil dari itemset 2 yang memenuhi syarat minimum support 3\%. Berikut merupakan perhitungan confidence dari masing-masing aturan asosiasi. Tabel 5 merupakan perhitungan confidence.

Tabel 5. Pembentukan aturan asosiasi

\begin{tabular}{llcc}
\hline Itemset & Transaksi AB & Transaksi A & Confidence \\
\hline JIKA MEMBELI & 13 & 24 & 0,542 \\
BAHAN ABU - & & & \\
ABU KOP MAKA & & & \\
AKAN MEMBELI & & & \\
BAHAN KOTAK- & & 34 & 0,382 \\
KOTAK KOP & & & \\
\hline JIKA MEMBELI & 13 & & \\
BAHAN KOTAK- & & & \\
KOTAK KOP & & & \\
MAKA AKAN & & & \\
MEMBELI BAHAN & & & \\
ABU - ABU KOP & & & \\
\hline JIKA MEMBELI & 8 & & \\
BAHAN KOTAK- & & & \\
KOTAK KOP & & & \\
MAKA AKAN & & & \\
MEMBELI BAHAN & & & \\
MUSLIM L1.5 P1 & & & \\
\hline JIKA MEMBELI & 8 & & \\
BAHAN MUSLIM & & & \\
L1.5 P1 MAKA & & & \\
AKAN MEMBELI & & & \\
BAHAN KOTAK- & & & \\
KOTAK KOP & & & \\
\hline JIKA MEMBELI & 14 & & \\
BAHAN KOTAK- & & & \\
KOTAK KOP & & & \\
MAKA AKAN & & & \\
MEMBELI LOGO & & & \\
AL IZHAR II & & & \\
\hline JIKA MEMBELI & & \\
LOGO AL IZHAR II & & & \\
\hline
\end{tabular}

\begin{tabular}{|c|c|c|c|}
\hline $\begin{array}{l}\text { MAKA AKAN } \\
\text { MEMBELI BAHAN } \\
\text { KOTAK-KOTAK } \\
\text { KOP } \\
\end{array}$ & & & \\
\hline $\begin{array}{l}\text { JIKA MEMBELI } \\
\text { BAHAN MUSLIM } \\
\text { L1.5 P1 MAKA } \\
\text { AKAN MEMBELI } \\
\text { LOGO AL IZHAR II }\end{array}$ & 35 & 44 & 0,795 \\
\hline $\begin{array}{l}\text { JIKA MEMBELI } \\
\text { LOGO AL IZHAR II } \\
\text { MAKA AKAN } \\
\text { MEMBELI BAHAN } \\
\text { MUSLIM L1.5 P1 }\end{array}$ & 35 & 52 & 0,673 \\
\hline $\begin{array}{l}\text { JIKA MEMBELI } \\
\text { BUKU AGENDA } \\
\text { KOP MAKA AKAN } \\
\text { MEMBELI BUKU } \\
\text { PENGHUBUNG SD }\end{array}$ & 14 & 29 & 0,483 \\
\hline $\begin{array}{l}\text { JIKA MEMBELI } \\
\text { BUKU } \\
\text { PENGHUBUNG SD } \\
\text { MAKA AKAN } \\
\text { MEMBELI BUKU } \\
\text { AGENDA KOP }\end{array}$ & 14 & 17 & 0,824 \\
\hline $\begin{array}{l}\text { JIKA MEMBELI } \\
\text { KAOS KAKI NO: } \\
\text { 17-18 MAKA } \\
\text { AKAN MEMBELI } \\
\text { KAOS KAKI NO: } \\
19-20\end{array}$ & 11 & 19 & 0,579 \\
\hline $\begin{array}{l}\text { JIKA MEMBELI } \\
\text { KAOS KAKI NO: } \\
\text { 19-20 MAKA } \\
\text { AKAN MEMBELI } \\
\text { KAOS KAKI NO: } \\
17-18\end{array}$ & 11 & 47 & 0,234 \\
\hline $\begin{array}{l}\text { JIKA MEMBELI } \\
\text { KAOS KAKI NO: } \\
\text { 19-20 MAKA } \\
\text { AKAN MEMBELI } \\
\text { KAOS KAKI NO: } \\
\text { 21-22 } \\
\end{array}$ & 15 & 47 & 0,319 \\
\hline $\begin{array}{l}\text { JIKA MEMBELI } \\
\text { KAOS KAKI NO: } \\
\text { 21-22 MAKA } \\
\text { AKAN MEMBELI } \\
\text { KAOS KAKI NO: } \\
\text { 19-20 } \\
\end{array}$ & 15 & 50 & 0,300 \\
\hline
\end{tabular}

\section{E. Aturan Asosiasi Final}

Sebuah transaksi dikatakan valid jika mempunyai nilai lift/improvement lebih dari 1 , yang berarti bahwa dalam transaksi tersebut item A dan item B benar-benar dibeli secara bersamaan. Lift ratio dapat dihitung dengan rumus:

Nilai Lift $=\frac{\text { Support } \mathrm{A} \cap \mathrm{B}}{\text { Support A X Support B }}$

Tabel 6. Aturan asosiasi final

\begin{tabular}{lccc}
\hline Itemset & Support & Confidence & $\begin{array}{c}\text { Lift } \\
\text { Rasio }\end{array}$ \\
\hline JIKA MEMBELI BAHAN & 0,054 & 0,542 & 3,855 \\
ABU - ABU KOP MAKA & & & \\
AKAN MEMBELI BAHAN & & & \\
KOTAK-KOTAK KOP & & & \\
\hline JIKA MEMBELI BAHAN & 0,033 & 0,382 & 3,855 \\
KOTAK-KOTAK KOP & & & \\
MAKA AKAN MEMBELI & & & \\
BAHAN ABU - ABU KOP & & & \\
\hline JIKA MEMBELI BAHAN & 0,058 & 0,412 & 1,916 \\
KOTAK-KOTAK KOP & & & \\
MAKA AKAN MEMBELI & & & \\
\hline
\end{tabular}




\begin{tabular}{lllc}
\hline Itemset & Support & Confidence & $\begin{array}{c}\text { Lift } \\
\text { Rasio }\end{array}$ \\
\hline LOGO AL IZHAR II & & & \\
\hline JIKA MEMBELI BAHAN & 0,145 & 0,795 & 3,702 \\
MUSLIM L1.5 P1 MAKA & & & \\
AKAN MEMBELI LOGO AL & & & \\
IZHAR II & & & \\
\hline JIKA MEMBELI LOGO AL & 0,058 & 0,673 & 3,702 \\
IZHAR II MAKA AKAN & & & \\
MEMBELI BAHAN MUSLIM & & & \\
L1.5 P1 & & & \\
\hline JIKA MEMBELI BUKU & 0,045 & 0,483 & 6,872 \\
AGENDA KOP MAKA & & & \\
AKAN MEMBELI BUKU & & & \\
PENGHUBUNG SD & & & \\
\hline JIKA MEMBELI BUKU & 0,062 & 0,824 & 6,872 \\
PENGHUBUNG SD MAKA & & & \\
AKAN MEMBELI BUKU & & & \\
AGENDA KOP & & & \\
\hline JIKA MEMBELI KAOS KAKI & 0,037 & 0,579 & 2,981 \\
NO: 17-18 MAKA AKAN & & & \\
MEMBELI KAOS KAKI NO: & & & \\
19-20 & & & \\
\hline JIKA MEMBELI KAOS KAKI & 0,033 & 0,319 & 1,545 \\
NO: $19-20$ MAKA AKAN & & & \\
MEMBELI KAOS KAKI NO: & & & \\
21-22 & & & \\
\hline JIKA MEMBELI KAOS KAKI & 0,041 & 0,300 & 1,545 \\
NO: 21-22 MAKA AKAN & & & \\
MEMBELI KAOS KAKI NO: & & & \\
19-20 & & & \\
\hline
\end{tabular}

F. Implementasi

Tampilan Implementasi Asosiasi pada Rapidminer

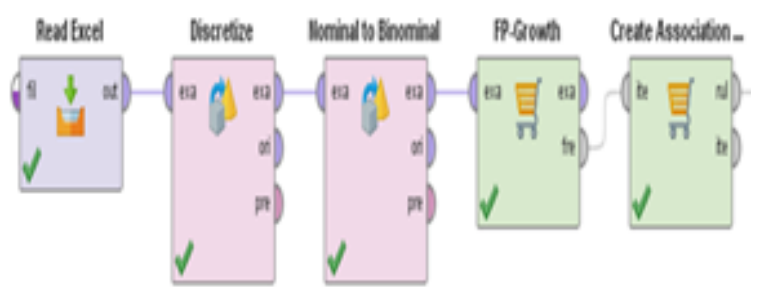

Gambar 1. Tampilan Implementasi Asosiasi pada Rapidminer

\begin{tabular}{|c|c|c|c|c|c|c|c|c|}
\hline i & Prasen & Coscuine & seon & Cotuna & Iowa & 6 & $H$ & If \\
\hline 1 & acsasio the & 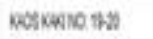 & $6 x$ & an & on & 481 & OHa & 1585 \\
\hline 2 & Nos own tas & noswono 262 & $W \%$ & 0249 & OOA & มพ & An & 1565 \\
\hline j & Bwetwastanos & Gunded-eudet & $t w$ & 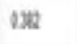 & ond & $\Delta w$ & OSE & two \\
\hline 4 & Bwactwotanos & IDCDKOURI & IVA & 149 & OMA & 421 & OMS & tws \\
\hline 1 & BWN KeOUCS & BNupecentousto & tw & 1012 & tose & 418 & die & int \\
\hline 1 & Havis. Buis? & BHeverusentuke? & WA & 289 & Ors & 416 & OLW & IMs \\
\hline$t$ & 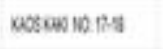 & nosicanio tha & twes & 295 & ONB & 218 & oto & 239 \\
\hline t & 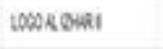 & 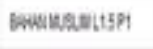 & 1465 & 49 & 018 & 435 & A 18 & $1 N$ \\
\hline ; & BeพusuLISh & เOCOKCONA! & ons & ons & oga & จ25 & 098 & $3 m$ \\
\hline t) & Buprotencso & Nurescike & \pm 3 & Ated & osit & 400 & ote & in \\
\hline
\end{tabular}

Gambar 2. Tampilan Implementasi Hasil Pembentukan Association Rules

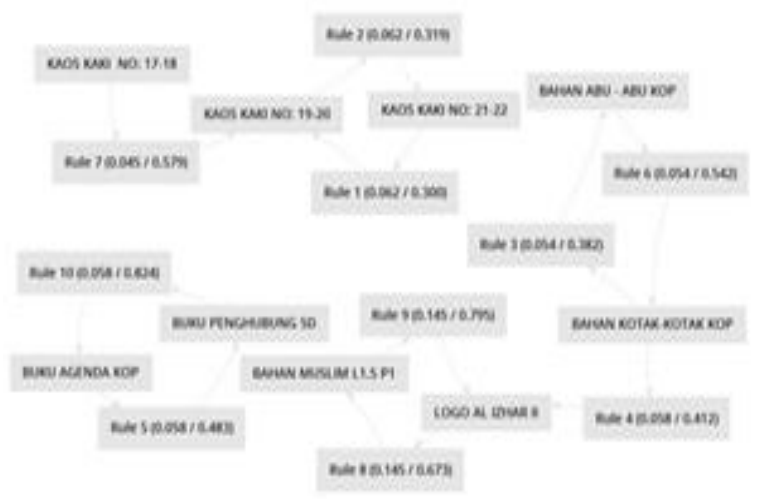

Gambar 3. Interprestasi Graph View

\section{AssociationRules}

ansociatios kiles

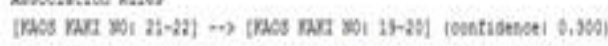

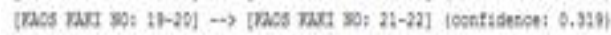

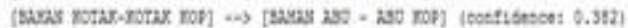

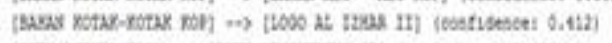

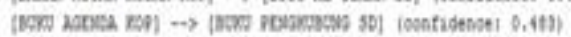

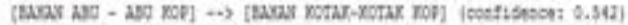

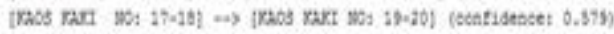

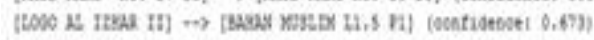

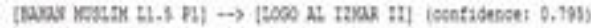

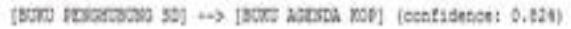

Gambar 4. Interpretasi Text View

\section{KESIMPULAN}

A. Kesimpulan

Dari uraian penelitian tersebut, maka dapat diambil kesimpulan bahwa data mining sangat berguna untuk mengetahui hubungan pada frekuensi penjualan perlengkapan sekolah yang paling sering dibeli oleh konsumen. Data mining merupakan teknologi yang sangat berguna untuk membantu Koperasi Karyawan yayasan Anakku menemukan informasi yang sangat penting dari gudang data yang selama ini tidak diketahui apa manfaatnya. Dengan metode algoritma apriori dapat disimpulkan bahwa penjualan perlengkapan sekolah yang paling banyak terjual dari 10 rule, adalah Jika membeli BAHAN MUSLIM L1.5P1 maka akan membeli LOGO AL IZHAR II dengan nilai support tertinggi sebesar $14,5 \%$ dan nilai confidance tertinggi 79,5\%. Dari Hasil aturan asosiasi final yang diketahui jika membeli KAOS KAKI NO:21-22 maka akan membeli KAOS KAKI NO:19-20 dengan nilai support 6,2\% dan nilai confidence 30\%. Jika membeli KAOS KAKI NO:1920 maka akan membeli KAOS KAKI NO:21-22 dengan nilai support $6,2 \%$ dan nilai confidence 
31,9\%. Jika membeli BAHAN KOTAK-KOTAK KOP maka akan membeli BAHAN ABU-ABU KOP dengan nilai support $5,4 \%$ dan nilai confidence $38,2 \%$. Jika membeli BAHAN KOTAK-KOTAK KOP maka akan membeli LOGO AL IZHAR II dengan nilai support 5,8\% dan nilai confidence 41,2\%. Jika membeli BUKU AGENDA KOP maka akan membeli BUKU PENGHUBUNG SD dengan nilai support $5,8 \%$ dan nilai confidence 48,3\%. Jika membeli BAHAN ABU-ABU KOP maka akan membeli BAHAN KOTAK-KOTAK KOP dengan nilai support $5,4 \%$ dan nilai confidence 54,2\%. Jika membeli KAOS KAKI NO:17-18 maka akan membeli KAOS KAKI NO:19-20 dengan nilai support 4,5\% dan nilai confidence 57,9\%. Jika membeli LOGO AL IZHAR II maka akan membeli BAHAN MUSLIM L1.5P1 dengan nilai support 14,5\% dan nilai confidence $67,3 \%$. Jika membeli BAHAN MUSLIM L1.5P1 maka akan membeli LOGO AL IZHAR II dengan nilai support $14,5 \%$ dan nilai confidence 79,5\%. Jika membeli BUKU PENGHUBUNG SD maka akan membeli BUKU AGENDA KOP dengan nilai support $5,8 \%$ dan nilai confidence $82,4 \%$. Hasil manual dan rapidminer itu bisa sama di karenakan melakukan berulang-ulang pengolahan data.

\section{B. Saran}

Dari uraian penelitian tersebut maka saran yang dapat diberikan sebaiknya pihak Koperasi Karyawan Yayasan Anakku menempatkan produk berupa perlengkapan sekolah dengan strategi promosi dan diskon sesuai rule yang telah dihasilkan dalam penelitian ini, sehingga akan memudahkan pelanggan dalam memilih produk berupa perlengkapan sekolah. Sebaiknya untuk penelitian selanjutnya diharapkan data yang digunakan akan dikembangkan dengan pengolahan data menggunakan metode lain selain algoritma apriori. Dan ada pengembangan variabel produk lainnya untuk dapat menentukan strategi penjualan toko secara menyeluruh di Koperasi Karyawan Yayasan Anakku. Sebaiknya pada penelitian selanjutnya dibuat aplikasi yang dapat mengolah perhitungan algoritma apriori.

\section{REFERENSI}

Aediyansyah, A. (2018). PERANCANGAN SISTEM INFORMASI PENJUALAN DAUR ULANG BOTOL BEKAS (PET) BERBASIS WEB. Jurnal Riset Informatika, 1(1), 11-16. Retrieved from

http://ejournal.kresnamediapublisher.com/i ndex.php/jri/article/view/5

Lisnawanty, L., \& Kurniawan, B. (2019). SISTEM
INFORMASI AKUNTANSI PENERIMAAN DAN PENGELUARAN KAS BERBASIS WEB (STUDI KASUS: PT. SINAR KAPUAS CEMERLANG). Jurnal Riset Informatika, 1(4), 187-196. https://doi.org/10.34288/jri.v1i4.101

Nere, M., \& Buani, D. C. P. (2018). PENERAPAN METODE WATERFALL PADA SISTEM INFORMASI JASA LAUNDRY (SIJALY) JENSCHAX LAUNDY BEKASI. Jurnal Techno Nusa Mandiri, 15(2), 69-76. https://doi.org/10.33480/TECHNO.V15I2.1 4

Oktaviani, A., TM Napitupul, G., Sarkawi, D., \& Yulianti, I. (2019). PENERAPAN DATA MINING TERHADAP PENJUALAN PIPA PADA CV. GASKINDO SENTOSA MENGGUNAKAN METODE ALGORITMA APRIORI. Jurnal Riset Informatika, 1(4), 167-172. https://doi.org/10.34288/jri.v1i4.96

Sikumbang, E. D. (2018). Penerapan Data Mining Penjualan Sepatu Menggunakan Metode Algoritma Apriori. Jurnal Teknik Komputer, 4(1), 156-161. https://doi.org/10.31294/jtk.v4i1.2560

Susilo, A. A. T. (2018). Penerapan Algoritma Apriori pada Pengolahan Data Transaksi Penjualan di Minimarket Priyo Kota Lubuklinggau. JTKSI, 1(3), 39-46.

Wijayanti, I., Nur, D. I., \& B, G. S. (2016). ANALISIS NILAI PERUSAHAAN PADA SEKTOR PERTAMBANGAN BATUBARA DI BURSA EFEK INDONESIA. Ekuilibrium : Jurnal Ilmiah Bidang Ilmu Ekonomi, 11(2), 107. https://doi.org/10.24269/ekuilibrium.v11i2 .211 